\title{
Effects of lignocaine on bidirectional tachycardia and on digitalis-induced atrial tachycardia with block
}

\author{
AGUSTIN CASTELLANOS, JULIO FERREIRO, KYRIACOS PEFKAROS, \\ JOHN J ROZANSKI, FEDERICO MOLEIRO, ROBERT J MYERBURG
}

From the Division of Cardiology, Department of Medicine, University of Miami School of Medicine, Miami, Florida, USA

SUMMARY Most recent studies discussing tachycardias with alternating QRS polarity have referred to those known as torsade de pointes. This report, in contrast, deals with bidirectional tachycardia and the effects of lignocaine on 10 patients with this arrhythmia. Three of the patients also had digitalisinduced atrial tachycardia with block. In one patient, a single bolus of lignocaine was followed (five minutes later) by ventricular fibrillation, but the other nine patients received two boluses of $75 \mathrm{mg}$ followed by a drip infusion of $3 \mathrm{mg} / \mathrm{min}$. The drug terminated the episodes of atrial tachycardia with block and bidirectional tachycardia in all patients thus treated. Whereas the abolition of the bidirectional tachycardia was permanent in the seven patients with digitalis intoxication, it recurred after stopping the drip infusion in the two patients without digitalis toxicity. It is concluded that lignocaine can be useful in the treatment of digitalis-induced bidirectional tachycardia and atrial tachycardia with block. From this study no conclusions can be drawn, however, as to whether lignocaine is superior to other class I or class IV agents.

Few papers published during the last 15 years have discussed the treatment of bidirectional tachycardia. ${ }^{1-7}$ Since most articles appeared before the use of lignocaine became widespread, it seemed of interest to present our experience with this drug in patients with bidirectional tachycardia, placing additional emphasis on the effects of lignocaine on digitalisinduced atrial tachycardia with block.

\section{Subjects and methods}

For the purpose of this paper, bidirectional tachycardia was considered as an electrocardiographic pattern resulting from the existence (or coexistence) of one or more ectopic (atrioventricular junctional or ventricular) rhythms with the following characteristics (Fig. 1) ${ }^{1-7}$ : (a) prolonged intraventricular conduction time; (b) QRS morphology different from that (previously or subsequently) produced by supraventricular impulses; (c) standard leads showing alternation in polarity caused by beat-to-beat variations in ÂQRS (from abnormal left axis deviation to right axis devia-

Accepted for publication 16 February 1982 tion); and (d) "incomplete", or "complete", right bundle-branch block pattern in lead V1.

There were 10 patients with bidirectional tachycardia but the effects of properly administered intravenous lignocaine were studied in only nine since in case 1 ventricular fibrillation appeared about five minutes after administration of a single bolus of $75 \mathrm{mg}$ (Fig. 2). In these nine patients an initial $75 \mathrm{mg}$ bolus was followed three minutes later by a second $75 \mathrm{mg}$ bolus, at which time a drip infusion (of $3 \mathrm{mg}$ / min) was started. The infusion was maintained for a seven hour period during which time the patients were continuously monitored in an intensive care unit by trained personnel.

In the Table, however, data from the 10 patients (six men and four women) are presented. The ages of the patients ranged between 43 and 77 years. Four patients with atherosclerotic heart disease and one patient with hypertrophic cardiomyopathy had moderate to severe congestive heart failure. Three patients had chronic lung disease with acute respiratory failure. Two patients had mitral valve prolapse and palpitation caused by documented paroxysmal tachyarrhythmias.

In three patients (Table) His bundle recordings 
Table Data on patients with bidirectional tachycardia (BT)

\begin{tabular}{|c|c|c|c|c|c|c|c|c|c|}
\hline $\begin{array}{l}\text { Case } \\
\text { No. }\end{array}$ & $\begin{array}{l}\text { Age } \\
\text { (y) }\end{array}$ & Aetiology & $\begin{array}{l}\text { Clinical } \\
\text { digitalis } \\
\text { toxicity }\end{array}$ & $\begin{array}{l}\text { Serum } \\
\text { digoxin } \\
(\text { nmol/l) })^{\star}\end{array}$ & $\begin{array}{l}\text { Presumed } \\
\text { dosage of } \\
\text { digoxin }\end{array}$ & $\begin{array}{l}\text { Recurrence } \\
\text { of } B T 30 \text { min } \\
\text { after lignocaine }\end{array}$ & $\begin{array}{l}\text { Effects of } \\
\text { lignocaine } \\
\text { (2 boluses) }\end{array}$ & $\begin{array}{l}\text { Effects of } \\
\text { lignocaine } \\
\text { (drip) }\end{array}$ & $\begin{array}{l}\text { Potassium } \\
(\text { mmol/l) }\end{array}$ \\
\hline $\begin{array}{l}1 \\
2 \\
3\end{array}$ & $\begin{array}{l}69 \\
77 \\
71\end{array}$ & $\begin{array}{l}\text { AHD } \\
\text { AHD } \\
\text { AHD }\end{array}$ & $\begin{array}{l}? \\
\text { Yes } \\
\text { Yes }\end{array}$ & $\begin{array}{l}8 \cdot 3 \\
5.8 \\
3.8\end{array}$ & $\begin{array}{l}? \\
0.25 \\
0.25 \text { (?) }\end{array}$ & $\begin{array}{l}\overline{\text { No }} \\
\text { No }\end{array}$ & $\begin{array}{l}t \\
\text { A of BT } \\
\text { TA of BT }\end{array}$ & $\begin{array}{l}\bar{A} \text { of PAT } \\
\text { A of BT and } \\
\text { PAT }\end{array}$ & $\begin{array}{l}? \\
3 \cdot 9 \\
4 \cdot 2\end{array}$ \\
\hline 4 & 68 & AHD & Yes & $4 \cdot 2$ & 0.75 & No & TA of BT & $\begin{array}{l}\text { A of BT and } \\
\text { PAT }\end{array}$ & $4 \cdot 3$ \\
\hline $\begin{array}{r}5 \\
6 \\
7 \\
8 \\
9 \\
10\end{array}$ & $\begin{array}{l}63 \\
67 \\
61 \\
49 \\
43 \\
47\end{array}$ & $\begin{array}{l}\text { CLD } \\
\text { CLD } \\
\text { CLD } \\
\text { C } \\
\text { MVP } \\
\text { MVP }\end{array}$ & $\begin{array}{l}\text { No } \\
\text { No } \\
\text { No } \\
\text { No } \\
\text { No } \\
\text { No }\end{array}$ & $\begin{array}{l}4 \cdot 4 \\
2 \cdot 0 \\
3 \cdot 1 \\
9 \cdot 0 \\
\text { NM } \\
\text { NM }\end{array}$ & $\begin{array}{l}0.75 \\
0.75 \\
1.2 \\
0.5 \\
? \\
?\end{array}$ & $\begin{array}{l}\text { No } \\
\text { No } \\
\text { No } \\
\text { No } \\
\text { Yes } \\
\text { Yes }\end{array}$ & $\begin{array}{l}\text { None } \\
\text { TA of BT } \\
\text { None } \\
\text { TA of BT } \\
\text { None } \\
\text { None }\end{array}$ & $\begin{array}{l}A \text { of BT } \\
A \text { of BT } \\
\text { A of BT } \\
\text { A of BT } \\
\text { A of BT } \\
\text { A of BT }\end{array}$ & $\begin{array}{l}2 \cdot 9 \\
2 \cdot 5 \\
3 \cdot 1 \\
3 \cdot 9 \\
4 \cdot 2 \\
4 \cdot 4\end{array}$ \\
\hline
\end{tabular}

AHD, atherosclerotic heart disease; CLD, chronic lung disease; C, cardiomyopathy; MVP, mitral valve prolapse; A, abolition; TA, transien abolition; BT, bidirectional tachycardia; PAT, paroxysmal atrial tachycardia with AV block; NM, serum digoxin not measured. $\star 1 \mathrm{ng}$ digoxin $\approx 1.28 \mathrm{nmol}$.

tReceived only one bolus (see text).

were performed (after explaining the procedure and obtaining informed consent) within the first 60 minutes after the start of the drip infusion. The techniques used in our department to perform these studies have been described previously. ${ }^{89}$ Plasma concentration of lignocaine was obtained in two patients.

\section{Results}

Before lignocaine administration the ventricular rates of bidirectional tachycardia ranged between 140 and $188 / \mathrm{min}$. All 10 patients had alternation between QRS complexes displaying different right bundle-branch block morphologies in lead V1. No patient had a left bundle-branch block morphology in V1. The coexistence of the following independent rhythms could be documented while bidirectional tachycardia was present: sinus rhythm (three patients), paroxysmal atrial tachycardia with block (one patient), and atrial fibrillation (one patient).

Clinical symptoms compatible with digoxin toxicity (nausea and vomiting) were present in three of eight patients without mitral valve prolapse. Plasma digoxin levels were raised 3.8 to $8.9 \mathrm{nmol} / 1$ ( 3 to 7 $\mathrm{ng} / \mathrm{ml}$ ) in six of these eight patients. Digoxin levels were not high in two patients with chronic lung disease $(2.0$ to $3.1 \mathrm{nmol} / 1$, respectively). The appropriate clinical setting and the low serum potassium levels, however ( 2.5 and $3.1 \mathrm{mmol} / 1$, respectively), strongly suggested digoxin toxicity.

Plasma lignocaine levels obtained in two patients were as follows: 4 and $4.5 \mathrm{mg} / 1$ at the point at which the drip infusions were started; 2.5 and $3 \mathrm{mg} / 130$ minutes afterwards; and 2.2 and $2.5 \mathrm{mg} / 190$ minutes afterwards.

His bundle recordings performed (in three cases) while the bidirectional tachycardia was occurring intermittently disclosed that in sinus beats there was a properly timed $\mathrm{H}$ deflection in front of the corresponding ventricular complexes. The ventricular origin of bidirectional tachycardia was corroborated in two of these patients because the wide QRS complexes were not preceded by $\mathrm{H}$ deflections. The remaining patient with normal $\mathrm{HV}$ intervals in sinus beats $(50 \mathrm{~ms})$, however, had short $\mathrm{HV}$ intervals during bidirectional tachycardia. Fig. 3 (left panel) depicts a short HV interval of $30 \mathrm{~ms}$ in the beat having a left posterior hemiblock/"incomplete" right bundlebranch block pattern and an HV interval of $0 \mathrm{~ms}$ in the beats with a left anterior hemiblock/"incomplete" right bundle-branch block morphology. This suggested that impulse formation occurred below the His bundle, presumably in two left "fascicular" sites. Conceptually, "fascicular" rhythms (or tachycardias) are "ventricular" since they arise below the bifurcation of the His bundle. 910

\section{EFFECTS OF LIGNOCAINE BOLUSES (Table)}

The initial two boluses had the following effects: (a) permanent suppression in one patient; (b) transient abolition with subsequent recurrences in four patients (Fig. 1 and 3); and (c) neither transient nor permanent suppression in four patients (Fig. 4).

EFFECTS OF DRIP INFUSION (Table)

Eight patients still had some episodes of bidirectional tachycardia while the drip infusion of lignocaine was being administered. Whereas in two of these eight patients bidirectional tachycardia was abolished in an "all-or-none" fashion (that is, with both types of complexes disappearing at the same time), in the remaining six patients termination occurred more gradually. The initial disappearance of the alternation in standard leads was replaced by multiform ectopic ventricular beats, some of which had a contour similar 


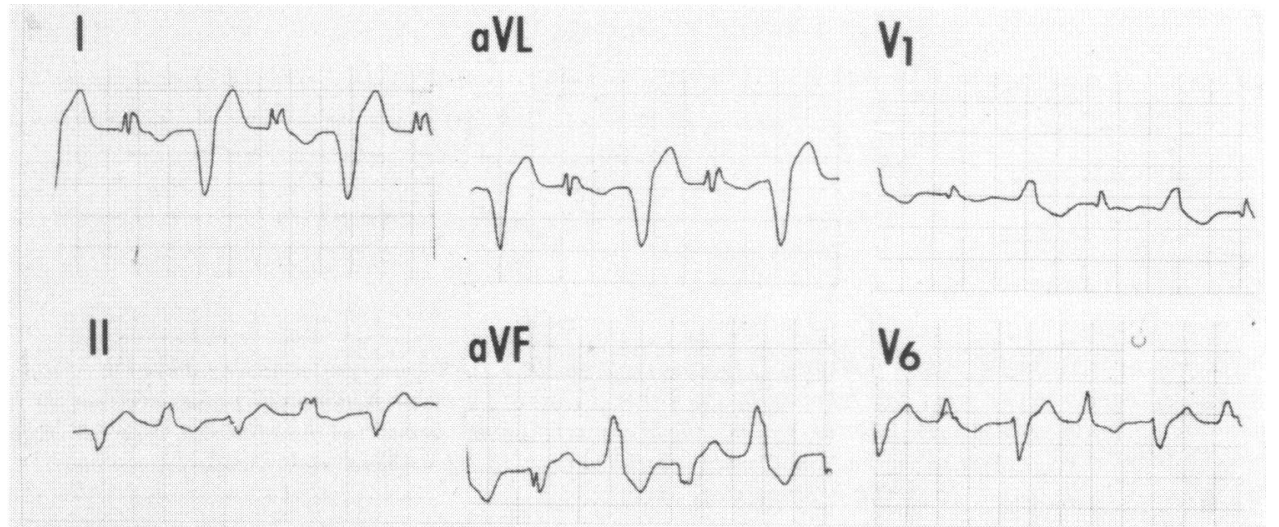

After lignocane boluses

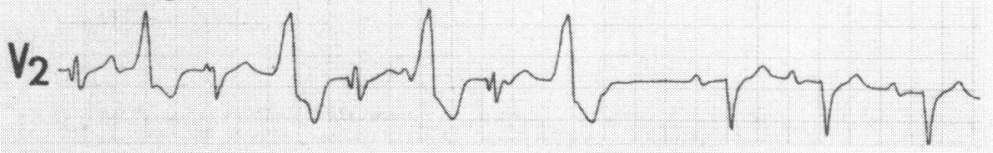

10 min after starting lignocaine drip

II

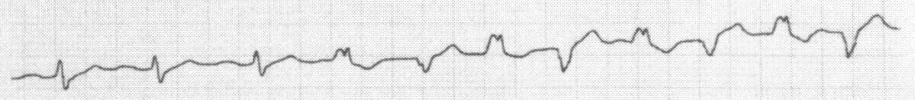

Fig. 1 The top two rows show the "classic" electrocardiographic pattern of bidirectional tachycardia with alternation in polarity in leads I, II, aVL, aVF, and V6; and alternation in morphology only in lead VI. Bidirectional tachycardia disappeared (temporarily) in the third strip (after the initial two boluses of lignocaine) to reappear 10 minutes after having started the drip infusion.

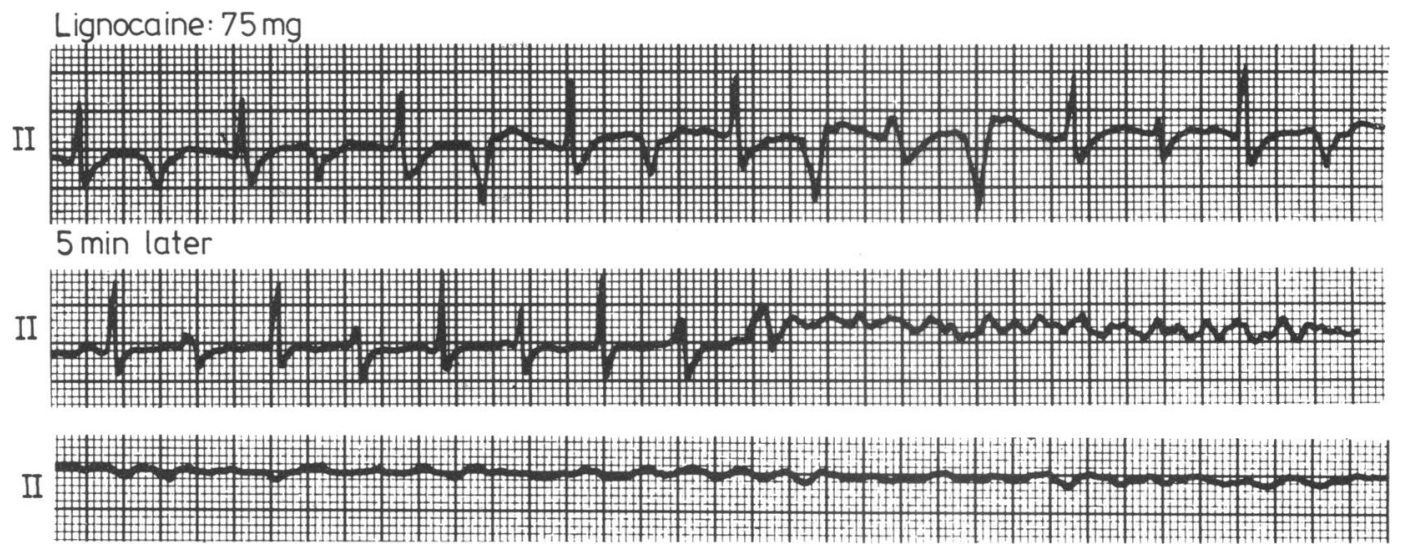

Fig. 2 Tracing from the patient who received a bolus of $75 \mathrm{mg}$. Note that ventricular fibrillation occurred five minutes after the end of the injection.

to that of the ventricular complexes present during bidirectional tachycardia. All episodes of bidirectional tachycardia had gone by between 1.45 and 2.15 hours after the start of the drip infusion. When the bidirectional tachycardia ended five patients had sinus rhythm, one had atrial fibrillation, and three had atrial tachycardia with block. The latter arrhythmia was also suppressed by the drip infusion of lignocaine (Fig. 5). Initially there was a gradual decrease in the ectopic atrial rate which resulted in a change from second degree to 1:1 atrioventricular conduction. Consequently, the ventricular rate increased. As more 

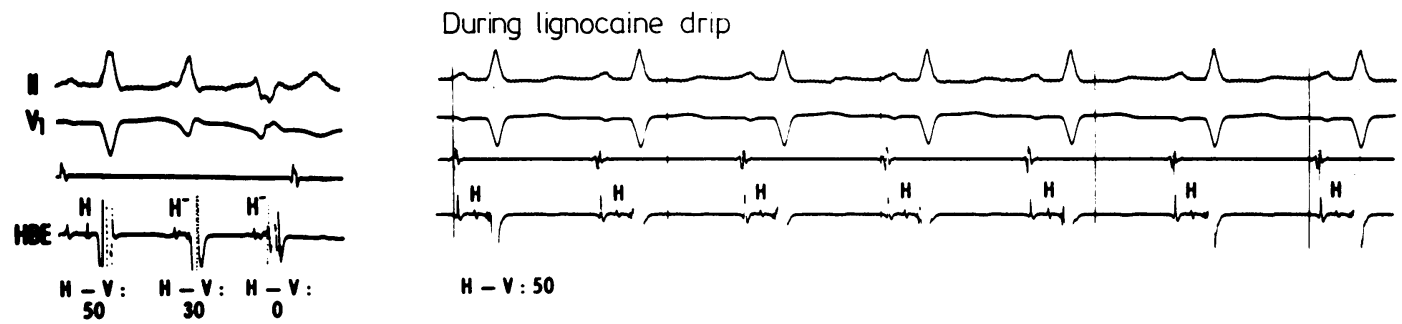

$H-V: 50$

Fig. 3 His bundle recording obtained 25 minutes (left panel) and one hour (right panel) after having started the idrip infusion. The left panel shows a sinus beat followed by the first two beats of the bidirectional tachycardia. Whereas the first (apparently normal for this patient) $H V$ interval is $50 \mathrm{~ms}$, the HV intervals of the second and third (ectopic) beats are shorter than normal (30 and $0 \mathrm{~ms}$, respectively). The latter, when associated with an "incomplete" right bundle-branch block "pattern" in lead V1, suggests a "fascicular" (ventricular) origin.

Lignocaine: $75 \mathrm{mg}$ (first bolus)

II
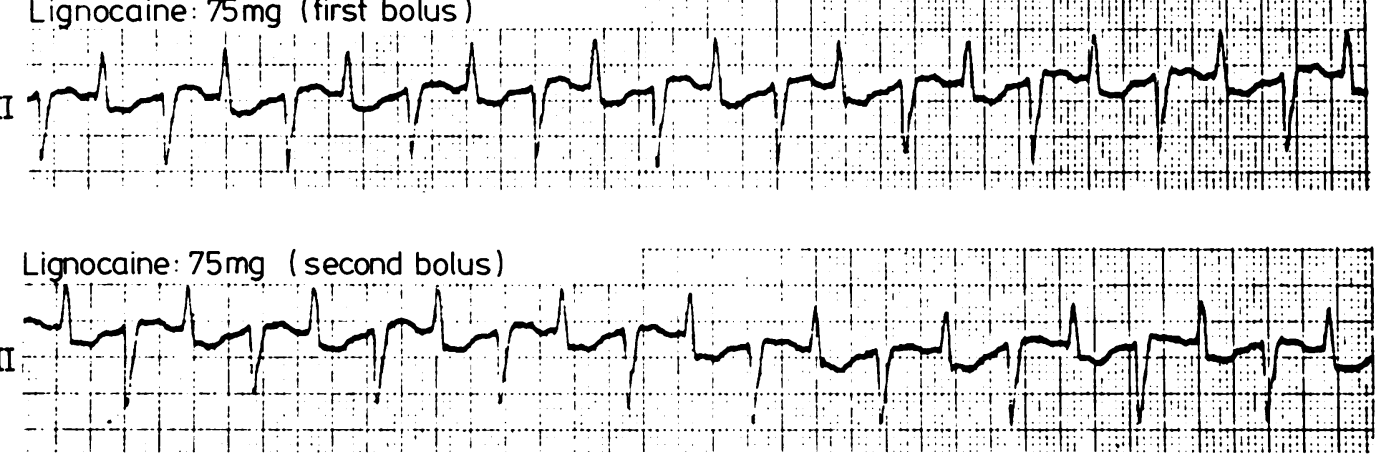

Fig. 4 Bidirectional tachycardia not abolished by the initial two boluses of lignocaine.

\section{Lignocaine drip (lead II)}

A

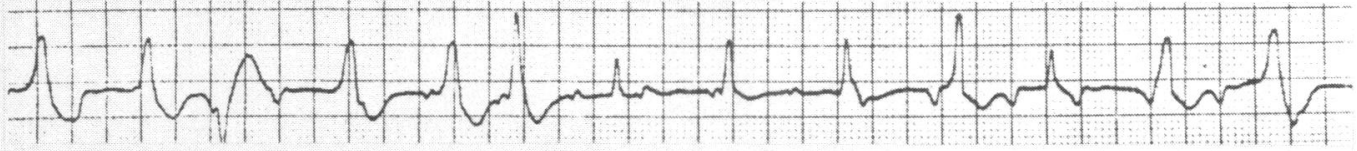

B

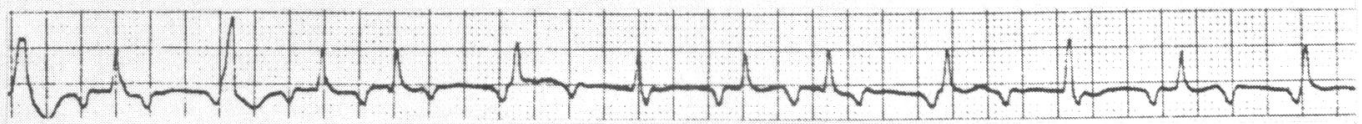

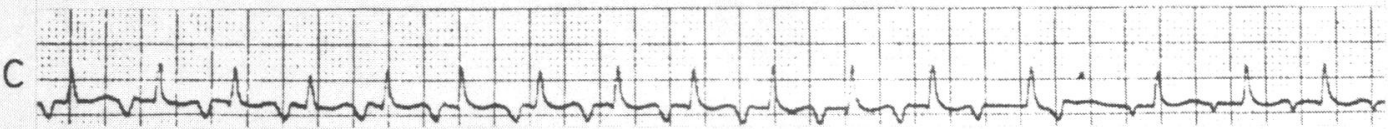

D

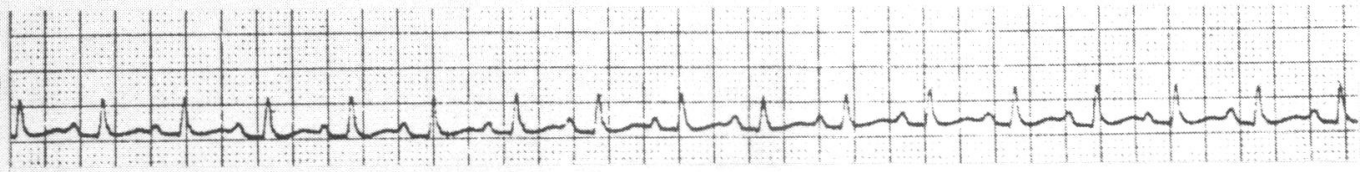

Fig. 5 (same patients as in Fig. 4) Effects of the drip infusion of lignocaine on the atrial tachycardia with block (caused by digoxin toxicity) which became manifest after bidirectional tachycardia was abolished. These effects were similar to those which had been previously reported with the use of intravenous potassium and procainamide. ${ }^{18}$ 
lignocaine was infused, the atrial (and ventricular) rates became progressively slower until the sinus node was able to take over.

After stopping the lignocaine drip (at the end of six hours) six patients had a 60 minute period of sinus rhythm without ventricular ectopic activity. Unifocal ventricular extrasystoles still occurred, however, in the two patients with mitral valve prolapse. Paroxysms of bidirectional tachycardia recurred 30 to $\mathbf{4 0}$ minutes later in these two patients. In the remaining patient (with chronic atrial fibrillation) it could not be determined if the wide QRS complexes that were present resulted from aberration of supraventricular impulses or from ectopic ventricular activity. These wide ventricular complexes did not resemble the QRS complexes which had constituted the bidirectional tachycardia.

\section{Discussion}

\section{SITE OF ORIGIN OF BIDIRECTIONAL}

\section{TACHYCARDIA}

All published reports dealing with intracardiac studies in patients with ectopic bidirectional tachycardia have shown its infra-atrioventricular junctional (ventricular) origin. ${ }^{1-7910}$ This finding was corroborated by His bundle recordings in three of our patients.

\section{EFFECTS OF LIGNOCAINE}

Lignocaine (a class I agent) was used because in our hospital this is the drug first administered to treat those arrhythmias initially diagnosed as "ventricular". Thus, no conclusions can be drawn as to whether lignocaine is superior to potassium salts, drugs that cause depression of slow inward calcium current, or other class I agents such as diphenylhydantoin, procainamide, and quinidine. ${ }^{11}$

Class I agents act essentially by depressing the fast inward sodium current (fast response). ${ }^{11}$ They decrease action potential amplitude, prolong the effective refractory period, and depress phase 4 depolarisation. Lignocaine and diphenylhydantoin, however, shorten action potential duration while procainamide and quinidine lengthen it. 11

According to Vaughan-Williams, lignocaine shortens action potential duration in those fibres where it was previously longest. Hence, action potential duration becomes more uniform. ${ }^{11}$ This effect, combined with the depression of phase 4 depolarisation, may have been responsible for the suppression of the arrhythmias occurring in our patients (which could have resulted from the association of automaticity and conduction disturbances).

In all cases, lignocaine proved to be effective when it could be administered adequately according to its well known pharmacological properties. ${ }^{12-15}$ The clin- ical course, and the plasma concentrations of lignocaine that were observed in two patients, suggested that the effectiveness of this drug was indeed related to its pharmacokinetics. ${ }^{13}{ }^{15}$ For example, it is known that after a single intravenous injection, lignocaine follows a two-compartment exponential disappearance curve. ${ }^{14}$ Diffusion through the body from the central compartment is first order, with a distribution half time of five to 10 minutes, equilibration through the body thereby requiring 20 to 40 minutes. The elimination of half time is around two hours. ${ }^{15}$

Case 1 developed ventricular fibrillation five minutes after a single dose of lignocaine. It is possible that ventricular fibrillation occurred at a time when "subtherapeutic" plasma lignocaine levels were present.

The two patients with drug-unrelated bidirectional tachycardia had milder symptoms than those with digitalis-induced arrhythmias. Furthermore, bidirectional tachycardia recurred after stopping lignocaine. Thus, more studies of these types of bidirectional tachycardia appear warranted.

Lignocaine is generally not considered to be a useful drug in the treatment of supraventricular arrhythmias. ${ }^{1617}$ This study showed, however, that it was capable of abolishing atrial tachycardia with block caused by digitalis toxicity. Moreover, the electrocardiographic effects were similar to those produced by intravenous potassium and procainamide, as previously reported by Lown et al. ${ }^{18}$ The initial effect of lignocaine, potassium, and procainamide is a decrease in the atrial rate which, when of sufficient magnitude, converts the second degree atrioventricular block into 1:1 atrioventricular conduction, thereby increasing the ventricular rate. This gradual decrease in the atrial rate (and therefore of the ventricular rate) continues until the sinus node takes over.

As stated by Lown et al., ${ }^{18}$ the infusion should not be stopped when the ventricular rate increases. On the contrary, it has to be continued since this is the response expected before conversion to sinus rhythm.

\section{References}

1 Pick A, Langendorf R. Interpretation of complex arrhythmias. Philadelphia: Lea \& Febiger, 1979: 115-7.

2 Castellanos A, Sung RJ, Myerburg RJ. Bidirectional tachycardia. In: Narula ON, ed. Cardiac arrhythmias. Electrophysiology, diagnoses and management. Baltimore: Williams \& Wilkins, 1979; 419-35.

3 Cohen SI, Deisseroth A, Hecht HS. Infra-His bundle origin of bidirectional tachycardia. Circulation 1973; 47: 1260-6.

4 Morris SN, Zipes DP. His bundle electrocardiography during bidirectional tachycardia. Circulation 1973; 48: $32-6$. 
5 Kastor JA, Goldreyer BN. Ventricular origin of bidirectional tachycardia. Circulation 1973; 48: 897-903.

6 Cohen SI, Voukydis P. Supraventricular origin of bidirectional tachycardia: report of a case. Circulation 1974; 50: 634-8.

7 Puech P, Grolleau R, Baissus C, Cabasson J, Latour H. Tachycardie bidirectionnelle d'origine infrahisienne. Arch Mal Coeur 1974; 67: 39-50.

8 Sung RJ, Castellanos A, Mallon SM, Gelband H, Mendoza IJ, Myerburg RJ. Mode of initiation of reciprocating tachycardia during programmed ventricular stimulation in the Wolff-Parkinson-White syndrome. Am $\mathcal{f}$ Cardiol 1977; 40: 24-31.

9 Castillo CA, Castellanos A Jr, Agha AS, Myerburg RJ. Significance of His bundle recordings with short $\mathrm{H}-\mathrm{V}$ intervals. Chest 1971; 60: 142-50.

10 Cohen $H$, Langendorf $R$, Pick A. Intermittent parasystole-mechanism of protection. Circulation 1973; 48: 761-74.

11 Vaughan-Williams EM. Review of the classification of antiarrhythmic drugs. In: Bayes de Luna A, Cosin J, eds. Diagnosis and treatment of cardiac arrhythmias. New York: Pergamon Press, 1979: 149-64.

12 Lieberman NA, Harris RS, Katz RL, Lipschutz HM, Dolgin M, Fisher VJ. Studies of the effects of lidocaine on the electrical and mechanical activity of the heart (abstract). Bull NY Acad Med 1967; 43: 1216.

13 Sasyniuk BI, Ogilvie RI. Antiarrhythmic drugs: electrophysiological and pharmacokinetic considerations. Annu Rev Pharmacol Toxicol 1975; 15: 131-55.

14 Collinsworth KA, Kalman SM, Harrison DC. The clinical pharmacology of lidocaine as an antiarrhythmic drug. Circulation 1974; 50: 1217-30.

15 Nattel S, Zipes DP. Clinical pharmacology of old and new antiarrhythmic drugs. Cardiovasc Clin 1980; 11: $221-48$.

16 Grossman JI, Lubow LA, Frieden J, Rubin IL. Lidocaine in cardiac arrhythmias. Arch Intern Med 1968; 121: 396-401.

17 Kostis JB, Goodkind MJ, Gotzoyannis S, Gerber NH, Kuo PT. Effect of Lidocaine on the atrial fibrillation threshold. Am Heart f 1977; 94: 764-8.

18 Lown B, Marcus F, Levine HD. Digitalis and atrial tachycardia with block. N Engl F Med 1959; 260: 301-9.

Requests for reprints to Professor Agustin Castellanos, Cardiology (D-39), University of Miami School of Medicine, PO Box 016960, Miami, Florida 33101, USA. 